\title{
Botulinum toxin injection for the treatment of chronic anal fissure: uni- and multivariate analysis of the factors that promote healing
}

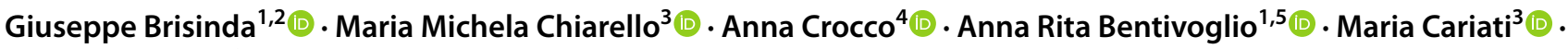 \\ Serafino Vanella ${ }^{6}[$
}

Accepted: 7 February 2022 / Published online: 11 February 2022

(c) The Author(s) 2022

\begin{abstract}
Purpose Anal fissure is caused by a pathological contraction of the internal anal sphincter. Lateral internal sphincterotomy remains the gold standard for the treatment of fissure. Botulinum toxin injections have been proposed to treat this condition without any risk of permanent injury of the internal sphincter. We investigate clinical and pathological variables and the effects of different dosage regimens of botulinum toxin to induce healing in patients with idiopathic anal fissure.

Methods This is a retrospective study at a single center. The patients underwent a pre-treatment evaluation that included clinical inspection of the fissure and anorectal manometry. We collected and analyzed demographic data, pathological variables, associated pathological conditions, and treatment variables. Success was defined as healing of the fissure, and improvement of symptoms was defined as asymptomatic persistent fissure.

Results The findings of 1003 patients treated with botulinum toxin injections were reported. At 2 months evaluation, complete healing was evident in 780 patients $(77.7 \%)$. Resting anal tone $(77.1 \pm 18.9 \mathrm{mmHg})$ was significantly lower from baseline $(P<0.0001)$ and from 1-month value $(P=0.0008)$. Thirty-nine not healed patients underwent lateral internal sphincterotomy, and 184 were re-treated with 50 UI of botulinum toxin. In these patients, the healing rate was $93.9 \%$ (171 patients). Dose and injection site of toxin correlates with healing rate. There were no relapses during an average of about 71 months.

Conclusion Our data show that injection of botulinum toxin into the internal anal sphincter is a safe and effective alternative to surgery in patients with chronic anal fissure.
\end{abstract}

Keywords Chronic anal fissure $\cdot$ Botulinum toxin $\cdot$ Lateral internal sphincterotomy

\section{Introduction}

Giuseppe Brisinda

gbrisin@tin.it; giuseppe.brisinda@policlinicogemelli.it

1 Università Cattolica del Sacro Cuore, Roma, Italy

2 Dipartimento Di Scienze Mediche E Chirurgiche, Fondazione Policlinico Universitario A Gemelli, IRCCS, Roma, Italy

3 Unità Operativa Di Chirurgia Generale, Ospedale San Giovanni Di Dio, Crotone, Italy

4 Unità Operativa Di Chirurgia Oncologica Della Tiroide E Della Paratiroide, Istituto Nazionale Tumori, IRCCS Fondazione Pascale, Napoli, Italy

5 Unità Operativa Di Neurologia, Fondazione Policlinico Universitario A Gemelli, IRCCS, Roma, Italy

6 Unità Operativa Di Chirurgia Generale E Oncologica, Azienda Ospedaliera San Giuseppe Moscati, Avellino, Italy
Chronic anal fissure (AF) is an ulcer of the distal anal canal. Fissure causes substantial morbidity in otherwise healthy people [1]. Most of the fissures are located at the posterior commissure [2,3]. Chronic AF is characterized by a marked reluctance to healing in the absence of treatment [4]. Spasm of the internal anal sphincter has been associated to chronic AF [5-7]. Treatment has focused on alleviating hypertonia of the sphincter. The most common surgical treatment is partial internal lateral sphincterotomy $[8,9]$. A recent systematic review demonstrates that healing rates were $95.13 \%$ in patients treated with sphincterotomy, although the benefit of surgical procedure was at a cost of increased complications, notably permanent incontinence [2]. A drawback of this surgery is its potential to cause minor but sometimes permanent alterations in gas, mucus, and occasionally, stool control [10, 11]: Mechanisms of continence can be acutely 
decompensated by the sphincterotomy, and incontinence can affect up to $35 \%$ of patients in the postoperative period [12-17].

To avoid the permanent sequelae of sphincterotomy, alternative treatments can be adopted-such as the injection of botulinum toxin or the topical application of nitro derivatives - to induce the healing of the fissure without permanent damage to the anal sphincters [18-23]. Several studies have documented that botulinum toxin injection is effective in the treatment of chronic AF [24-27]. Furthermore, a recent survey by the American Society of Colon and Rectal Surgeons have been documented that the injection of botulinum toxin for chronic AF is commonly used by colorectal surgeons and that there is a consensus on toxin dosage, administration site, technique, and also on the use of monitored anesthesia care [21].

We report the results of a retrospective non-randomized study of patients undergoing botulinum toxin injections for the treatment of chronic AF, in a 10 -year period. We collected and analyzed demographic data, pathological variables, associated pathological conditions, and treatment variables. To identify variables that promote the healing of $\mathrm{AF}$, a univariate and multivariate analysis was performed.

\section{Methods}

This is a retrospective study in a single center. A total of 1003 consecutive patients with symptomatic chronic AF were enrolled in the study. The diagnosis was based on the following clinical criteria: evidence of posterior circumscribed ulcer with a hypertrophic sentinel tag of skin, exposure of the horizontal fibers of the internal anal sphincter, and typical symptoms (post-defecatory pain, pain at a distance from evacuation and/or at night, bleeding) lasting for more than 2 months. Each patient had provided written informed consent.

Patients with acute fissure or chronic AF associated with other conditions (i.e., chronic inflammatory bowel disease, HIV infection, tuberculosis, sexually transmitted diseases, immunosuppression, and/or anorectal or perianal cancer) were excluded. Other exclusion criteria were systemic diseases with altered cholinergic transmission, use of medication capable of interfering with the action of the toxin (aminoglycosides, baclofen, dantrolene, or diazepam), pregnancy and/or breast-feeding, or known hypersensitivity to the components of the formulations.

\section{Clinical evaluation and baseline assessment}

Every patient underwent a pre-treatment evaluation that included clinical inspection of the fissure and anorectal manometry. Demographic data on age and gender were recorded in all patients. Data regarding anal pathology (duration and characteristics of the symptoms), association with other anal and/or systemic pathologies, allergies, and previous interventions were recorded for each patient. Also, stool consistency, the frequency and peculiarity of evacuations, and the use of laxatives or enemas were recorded for each patient. The resting and maximal squeeze anal canal pressures (i.e., the maximal voluntary increase in pressure above the resting pressure) were measured by stationary pull-through techniques.

\section{Preparation of the toxin and method of injection}

The botulinum toxin type A was diluted with saline solution. When the American formulation (Botox ${ }^{\circledR}$; Allergan, Irvine, California, USA) was used, the vials contained $100 \mathrm{IU}$ of type A botulinum toxin stored at a temperature of $-20{ }^{\circ} \mathrm{C}$ and diluted with saline solution at $50 \mathrm{IU} / \mathrm{ml}$, at the time of use; when the European formulation (Dysport ${ }^{\circledR}$; Spywood Biopharm, Wrexham, UK) was used, the vials contained 500 freeze-dried IU of type A botulinum toxin diluted in saline solution at $150 \mathrm{IU} / \mathrm{ml}$. A conversion factor of 1 to 3 (1 IU Botox = 3 IU Dysport) was adopted [28]. This conversion factor is due to the different potency of the two toxin preparations. In the text, when not otherwise specified, reference is made to Botox UI. After manually detecting the internal anal sphincter, the toxin was injected through a 27-gauge needle with the patient lying on his left side. The toxin was injected in the anterior or posterior commissure, or in both. No systemic sedation was administered during the procedure.

\section{Aim of the study}

The primary outcome was the complete healing after treatment. The treatment was considered successful if the fissure healed. Persistence of the fissure in the absence of specific symptoms was considered a symptomatic improvement.

\section{Follow-up}

Patients were re-examined at 1 and 2 months after the treatment. Each patient underwent a clinical evaluation and anorectal manometry. This approach was also used in patients who underwent rescue treatment. Clinical control was carried out by telephone interviews (once a year). All patients were given a dedicated telephone number to refer to in the event of specific symptoms (appearance of post-defecatory pain, bleeding after evacuation). Clinical visit was performed only in patients who complained of specific symptoms. In consideration of the reversibility of the treatment and, therefore, the reversibility of any complication, no score for the evaluation of fecal continence was used. 


\section{Statistical analysis}

Data were analyzed using standard statistical methods. Initially, a univariate analysis of all potential factors influencing the course of the disease was performed using the Chi-square test or Fisher's exact test for categorical data and the ANOVA test for continuous data in groups of more than two. Prespecified subgroups in these analyses were defined according to age ( $\leq 35$ years, 36 to 45 years, 46 to 60 years, or $>60$ years), duration of symptoms before treatment ( $\leq 7$ months or $>7$ months), number of evacuation for week ( $\leq 7$ or $>7$ evacuations/week), site of injection of the toxin (anterior injection, posterior injection, combined setting), number of units injected (from 15 to $100 \mathrm{IU}$ ), and dosage groups (low $\leq 25$ IU injected, medium $30 \mathrm{IU}$, and high 50-100 IU). Subsequently, a multivariate logistic regression was performed by building models that consider the potential factors influencing the healing rate that at univariate analysis had a value of $P<0.25$, according to the Hosmer-Lemeshow rule. Data were processed using GraphPad® Prism software (GraphPad, San Diego, USA). A value of $P<0.05$ was considered statistically significant, regardless of the test used.

\section{Results}

Demographic data and clinical characteristics of 1,003 patients with chronic AF treated at the General Surgery Operative Unit, Fondazione Policlinico Universitario "A Gemelli" IRCCS of Rome are reported in Table 1. Regarding the characteristics of the bowel movements, 459 patients (45.8\%) reported constipation, and 490 (48.9\%) increased bowel movements. Number of evacuations per week was less than 7 in $88.3 \%$ of cases. A forced evacuation was reported by 489 patients (48.8\%) and an incomplete evacuation by 262 patients (26.1\%). At baseline, a resting anal tone of $102.4 \pm 20.1 \mathrm{mmHg}$ and a voluntary contraction of $85.4 \pm 35.7 \mathrm{mmHg}$ has been documented.

In all patients, toxin was injected into the internal anal sphincter: dose and site of injection were reported in Table 2. In $94.1 \%$ of patients, no local anesthesia and/or sedation was required, and in $93.9 \%$ of patients, the sphincter was easily identified by simple digital palpation. Patients (5.9\%) received subcutaneous administration of local anesthetic, prior to the toxin injection. In one case, a local reaction occurred, consisting of a limited and modest skin rash, which resolved after 4 days following topical application of corticosteroids.

One month after treatment, healing was observed in 751 patients $(74.9 \%)$. A reduction in resting anal tone $(80.3 \pm 18.1 \mathrm{mmHg}, P<0.0001$ vs baseline value) and
Table 1 Analysis of parameters in 1,003 patients undergoing treatment with botulinum type A toxin for chronic fissure. The frequency and percentage for each individual variable considered are shown

\begin{tabular}{|c|c|c|c|}
\hline Parameters considered & Frequency & $\%$ & Cumulative \% \\
\hline $\begin{array}{l}\text { Age (years) } \\
\leq 35 \\
36-45 \\
46-60 \\
>60\end{array}$ & $\begin{array}{l}285 \\
247 \\
293 \\
178\end{array}$ & $\begin{array}{l}28.4 \\
24.6 \\
29.2 \\
17.7\end{array}$ & $\begin{array}{l}28.4 \\
53.0 \\
82.3 \\
100.0\end{array}$ \\
\hline $\begin{array}{l}\text { Sex } \\
\text { Male } \\
\text { Female }\end{array}$ & $\begin{array}{l}574 \\
429\end{array}$ & $\begin{array}{l}57.2 \\
42.8\end{array}$ & $\begin{array}{l}57.2 \\
100.0\end{array}$ \\
\hline $\begin{array}{l}\text { Duration of symptoms } \\
\leq 7 \text { months } \\
>7 \text { months }\end{array}$ & $\begin{array}{l}618 \\
385\end{array}$ & $\begin{array}{l}61.6 \\
38.4\end{array}$ & $\begin{array}{l}61.6 \\
100.0\end{array}$ \\
\hline $\begin{array}{l}\text { Post-operative pain } \\
\text { Present } \\
\text { Absent }\end{array}$ & $\begin{array}{l}985 \\
18\end{array}$ & $\begin{array}{l}98.2 \\
1.8\end{array}$ & $\begin{array}{l}98.2 \\
100.0\end{array}$ \\
\hline $\begin{array}{l}\text { Night-time pain } \\
\text { Present } \\
\text { Absent }\end{array}$ & $\begin{array}{l}179 \\
824\end{array}$ & $\begin{array}{l}17.8 \\
82.2\end{array}$ & $\begin{array}{l}17.8 \\
100.0\end{array}$ \\
\hline $\begin{array}{l}\text { Pain in the time } \\
\text { Present } \\
\text { Absent }\end{array}$ & $\begin{array}{l}269 \\
734\end{array}$ & $\begin{array}{l}26.8 \\
73.2\end{array}$ & $\begin{array}{l}26.8 \\
100.0\end{array}$ \\
\hline $\begin{array}{l}\text { Bleeding } \\
\text { Present } \\
\text { Absent }\end{array}$ & $\begin{array}{l}678 \\
325\end{array}$ & $\begin{array}{l}67.6 \\
32.4\end{array}$ & $\begin{array}{l}67.6 \\
100.0\end{array}$ \\
\hline $\begin{array}{l}\text { Loss of mucus } \\
\text { Present } \\
\text { Absent }\end{array}$ & $\begin{array}{l}28 \\
975\end{array}$ & $\begin{array}{r}2.8 \\
97.2\end{array}$ & $\begin{array}{c}2.8 \\
100.0\end{array}$ \\
\hline $\begin{array}{l}\text { Other anal disease } \\
\text { Present } \\
\text { Absent }\end{array}$ & $\begin{array}{l}126 \\
877\end{array}$ & $\begin{array}{l}12.6 \\
87.4\end{array}$ & $\begin{array}{l}12.6 \\
100.0\end{array}$ \\
\hline $\begin{array}{l}\text { Extra-anal disease } \\
\text { Present } \\
\text { Absent }\end{array}$ & $\begin{array}{l}86 \\
917\end{array}$ & $\begin{array}{r}8.6 \\
91.4\end{array}$ & $\begin{array}{c}8.6 \\
100.0\end{array}$ \\
\hline $\begin{array}{l}\text { Allergies } \\
\text { Present } \\
\text { Absent }\end{array}$ & $\begin{array}{l}9 \\
994\end{array}$ & $\begin{array}{r}0.9 \\
99.1\end{array}$ & $\begin{array}{c}0.9 \\
100.0\end{array}$ \\
\hline $\begin{array}{l}\text { Previous surgery } \\
\text { Yes } \\
\text { No }\end{array}$ & $\begin{array}{l}204 \\
799\end{array}$ & $\begin{array}{l}20.3 \\
79.7\end{array}$ & $\begin{array}{l}20.3 \\
100.0\end{array}$ \\
\hline $\begin{array}{l}\text { Bowel functions } \\
\text { Normal } \\
\text { Diarrhea } \\
\text { Constipation }\end{array}$ & $\begin{array}{l}497 \\
47 \\
459\end{array}$ & $\begin{array}{l}49.6 \\
4,7 \\
45.8\end{array}$ & $\begin{array}{l}49.6 \\
54.2 \\
100.0\end{array}$ \\
\hline $\begin{array}{l}\text { Consistence of stool } \\
\text { Shaped } \\
\text { Soft } \\
\text { Hard }\end{array}$ & $\begin{array}{l}472 \\
41 \\
490\end{array}$ & $\begin{array}{l}47.1 \\
4.1 \\
48.9\end{array}$ & $\begin{array}{l}47.1 \\
51.2 \\
100.0\end{array}$ \\
\hline $\begin{array}{l}\text { Number of weekly evacuation } \\
\leq 7 \\
>7\end{array}$ & $\begin{array}{l}887 \\
116\end{array}$ & $\begin{array}{l}88.4 \\
11.6\end{array}$ & $\begin{array}{l}88.4 \\
100.0\end{array}$ \\
\hline $\begin{array}{l}\text { Forced evacuation } \\
\text { Present } \\
\text { Absent }\end{array}$ & $\begin{array}{l}490 \\
513\end{array}$ & $\begin{array}{l}48.9 \\
51.1\end{array}$ & $\begin{array}{l}48.9 \\
100.0\end{array}$ \\
\hline $\begin{array}{l}\text { Incomplete evacuation } \\
\text { Yes } \\
\text { No }\end{array}$ & $\begin{array}{l}263 \\
740\end{array}$ & $\begin{array}{l}26.2 \\
73.8\end{array}$ & $\begin{array}{l}26.2 \\
100.0\end{array}$ \\
\hline
\end{tabular}


Table 1 (continued)

\begin{tabular}{llll}
\hline Parameters considered & Frequency & $\%$ & Cumulative \% \\
\hline Use of laxative & 379 & 37.8 & 37.8 \\
Yes & 624 & 62.2 & 100.0 \\
No & & & \\
Use of enemas & 235 & 23.4 & 23.4 \\
Yes & 768 & 76.6 & 100.0 \\
No & & & \\
\hline
\end{tabular}

maximal voluntary contraction $(76.5 \pm 23.9 \mathrm{mmHg}$, $P<0.0001$ vs baseline value) was observed.

At the 2 months evaluation, complete healing was apparent in 780 patients (77.7\%). Incontinence was not observed in any patient. Resting anal tone $(77.1 \pm 18.9 \mathrm{mmHg})$ was significantly lower from baseline $(P<0.0001)$ and from 1 -month value $(P=0.0008)$. Maximal voluntary contraction $(77 \pm 26.4 \mathrm{mmHg})$ was lower than the baseline value $(P<0.0001)$ and did not vary from 1 -month value $(P=0.6)$.

At 2-months evaluation, 223 patients $(22.3 \%)$ were not healed. Of these, 39 patients underwent lateral internal sphincterotomy, and 184 were treated with further injection of $50 \mathrm{UI}$ of botulinum toxin. In these latter group, the healing rate was $93.9 \%$ (171 patients). Incontinence has not been observed in any patient. Before the rescue treatment, a resting anal tone of $100.6 \pm 27.2 \mathrm{mmHg}$, and a voluntary contraction of $84.5 \pm 31.2 \mathrm{mmHg}$ has been documented in all the injected patients. At 1-month evaluation after rescue

Table 2 Results of treatment with botulinum toxin. Frequency and percentage are shown for each parameter

\begin{tabular}{|c|c|c|c|}
\hline & Frequency & $\%$ & Cumulative \% \\
\hline Dose of toxin (UI) & 89 & 8.9 & 8.9 \\
\hline 15 & 112 & 11.2 & 20.1 \\
\hline 20 & 3 & 0.3 & 20.4 \\
\hline 25 & 196 & 19.5 & 39.9 \\
\hline 30 & 599 & 59.7 & 99.6 \\
\hline 50 & 4 & 0.4 & 100.0 \\
\hline \multicolumn{4}{|l|}{100} \\
\hline Dosing group & 204 & 20.4 & 20.4 \\
\hline Low (15-25 UI) & 196 & 19.5 & 39.9 \\
\hline Medium (30 UI) & 603 & 60.1 & 100.0 \\
\hline \multicolumn{4}{|l|}{ High (50-100 UI) } \\
\hline Site of injection & 167 & 16.7 & 16.7 \\
\hline Posterior site & 814 & 81.2 & 97.8 \\
\hline Anterior site & 22 & 2.2 & 100.0 \\
\hline \multicolumn{4}{|c|}{$\begin{array}{l}\text { Combined site (poste- } \\
\text { rior + anterior) }\end{array}$} \\
\hline Local reactions & 1 & 0.1 & 0.1 \\
\hline Yes & 1002 & 99.9 & 100.0 \\
\hline \multicolumn{4}{|l|}{ No } \\
\hline Local anesthesia & 59 & 5.9 & 5.9 \\
\hline Yes & 944 & 94.1 & 100.0 \\
\hline No & & & \\
\hline
\end{tabular}

treatment, resting anal pressure and voluntary contraction were $69.5 \pm 17.6 \mathrm{mmHg}$ and $83.3 \pm 39.9 \mathrm{mmHg}$, respectively. At 2 months evaluation, resting anal pressure and maximal voluntary contraction were $68.5 \pm 14.3 \mathrm{mmHg}$ and $82.7 \pm 38.6 \mathrm{mmHg}$, respectively. Resting anal pressure was significantly lower than the baseline values $(P<0.0001)$ and did not vary from 1 -month value $(P=0.7)$. Maximal voluntary contraction did not differ significantly from baseline $(P=0.7)$ and from 1-month $(P=0.8)$ values.

The follow-up was performed as described above. Complete information for the first 3 years after treatment was obtained from 950 patients. None of them reported the appearance of symptoms and/or fecal incontinence, referred as uncontrolled losses of gas, mucus, and/or liquid stools. In the following years, 398 patients were lost to follow-up. The remaining 552 patients reported no post-defecatory pain or bleeding. All reported the absence of disorders related to fecal continence. The mean follow-up period was $71.4 \pm 38.6$ months.

At univariate analysis, no demographic parameters were shown to have a direct influence on healing (Table 3). Both age $(P=0.8)$ and sex $(P=0.5)$ showed no statistically significant difference. Among clinical variables, only pain after

Table 3 Results of the univariate analysis after 1 month follow-up from the treatment with botulinum toxin

\begin{tabular}{lc}
\hline Variable & $\begin{array}{c}\text { Univariate } \\
\text { analysis }(\boldsymbol{P} \\
\text { value) }\end{array}$ \\
\hline Age & 0.874 \\
Sex & 0.524 \\
Duration of symptoms & 0.413 \\
Post-defecatory pain & 0.301 \\
Night-time pain & 0.570 \\
Pain at distance from the evacuation & 0.004 \\
Bleeding & 0.065 \\
Loss of mucus & 0.154 \\
Other anal pathology & 0.966 \\
Extra-anal pathology & 0.749 \\
Allergies & 0.635 \\
Previous surgery & 0.910 \\
Bowel function & 0.712 \\
Consistency of stools & 0.656 \\
Weekly evacuations & 0.131 \\
Forced evacuations & 0.311 \\
Incomplete evacuations & 0.377 \\
Laxative use & 0.282 \\
Use of enemas & 0.675 \\
Toxin dose & $<0.0001$ \\
Dosing group & $<0.0001$ \\
Site of injection & $<0.0001$ \\
Local reactions & 0.755 \\
\hline & \\
\hline
\end{tabular}


Table 4 Findings of the univariate analysis to 2 months follow up after treatment with botulinum toxin

\begin{tabular}{|c|c|}
\hline Variable & $\begin{array}{l}\text { Univariate } \\
\text { analysis }(P \\
\text { value })\end{array}$ \\
\hline Age & 0.270 \\
\hline Sex & 0.953 \\
\hline Duration of symptoms & 0.566 \\
\hline Post-defecatory pain & 0.257 \\
\hline Night-time pain & 0.873 \\
\hline Pain at a distance from the evacuation & 0.02 \\
\hline Bleeding & 0.711 \\
\hline Loss of mucous & 0.494 \\
\hline Other anal disease & 0.888 \\
\hline Extra-anal disease & 0.824 \\
\hline Allergies & 0.189 \\
\hline Previous surgery & 0.095 \\
\hline Bowel function & 0.740 \\
\hline Consistency of stools & 0.781 \\
\hline Weekly evacuations & 0.272 \\
\hline Forced evacuations & 0.311 \\
\hline Incomplete evacuations & 0.192 \\
\hline Laxative use & 0.228 \\
\hline Use of enemas & 0.510 \\
\hline Toxin dose & $<0.0001$ \\
\hline Dosing group & $<0.0001$ \\
\hline Site of injection & $<0.0001$ \\
\hline Local reactions & 0.784 \\
\hline
\end{tabular}

evacuation showed influence on the healing $(P=0.04)$. The dose and injection site of the toxin correlate significantly with the healing rate. Healing was not observed in any cases treated with $15 \mathrm{IU}$, in 71 out of 112 treated with $20 \mathrm{IU}$, in 2 out of 3 with $25 \mathrm{IU}$, in 159 out of 195 with $30 \mathrm{IU}$, and in 450 out of 563 treated with $50 \mathrm{IU}(P<0.0001)$. The subdivision of the patient population into the 3 dosage groups (high, medium, and low) documents a healing rate of $81.5 \%$ in

Table 5 Results of multivariate analysis 1 month follow up from botulinum toxin treatment

\begin{tabular}{lrll}
\hline Variable & $\begin{array}{l}\text { Multivariate } \\
\text { analysis } \\
\text { (P value) }\end{array}$ & $\begin{array}{l}\text { T } \\
\text { Ratio }\end{array}$ & 95\%CI \\
\hline Age & 0.7664 & 0.2972 & -0.002253 to 0.001660 \\
Sex & 0.2318 & 1.197 & -0.02201 to 0.09102 \\
Pain at distance & 0.0008 & 3.361 & 0.04576 to 0.1738 \\
Bleeding & 0.0621 & 1.868 & -0.002802 to 0.1166 \\
Loss of mucus & 0.2642 & 1.117 & -0.07641 to 0.2790 \\
Evacuation/weekly & 0.8641 & 0.1712 & -0.007941 to 0.009462 \\
Dose of toxin & $<0.0001$ & 4.816 & 0.003161 to 0.007500 \\
Site of injection & 0.1404 & 1.476 & -0.1621 to 0.1150 \\
\hline
\end{tabular}

Table 6 Results of multivariate analysis 2 months follow-up after treatment with botulinum toxin

\begin{tabular}{llll}
\hline Variable & $\begin{array}{l}\text { Multivariate } \\
\text { analysis } \\
\text { (P value) }\end{array}$ & $\begin{array}{l}\text { T } \\
\text { ratio }\end{array}$ & 95\%CI \\
\hline Age & 0.3492 & 0.9369 & -0.003446 to \\
& & \multicolumn{3}{c}{0.001217} \\
Sex & 0.6985 & 0.3875 & -0.05314 to 0.07933 \\
$\begin{array}{l}\text { Pain at a distance } \\
\text { from the evacua- }\end{array}$ & 0.0521 & 1.946 & 0.0005432 to 0.1502 \\
$\quad$ tion & & & \\
$\begin{array}{l}\text { Incomplete evacu- } \\
\text { ation }\end{array}$ & 0.1011 & 1.642 & -0.01429 to 0.1619 \\
$\begin{array}{l}\text { Laxative use } \\
\text { Previous surgery }\end{array}$ & 0.0964 & 1.665 & -0.1438 to 0.01169 \\
$\begin{array}{l}\text { Allergies } \\
\text { Dose of toxin }\end{array}$ & 0.0465 & 1.995 & -0.001418 to 0.1601 \\
Site of injection & 0.6463 & 0.4591 & -0.2508 to 0.4042 \\
\hline
\end{tabular}

medium dosage group, compared to $79.5 \%$ and $51 \%$ in those treated with high or low dosages, respectively $(P<0.0001)$. Another variable found to be strongly correlated with healing is the injection site: healing was shown in $56.6 \%$ of patients treated with posterior injections and in $78.6 \%$ of those with anterior injection of the toxin $(P<0.0001)$. Two months after treatment (Table 4), a statistically significant influence in healing was found in patients with persistence of pain after the evacuation $(P=0.02)$. Similarly, to 1 -month evaluation, the dose significantly correlates with healing, observed in $29.2 \%, 75 \%, 79.3 \%$, and $83.9 \%$ of patients treated with $15 \mathrm{IU}, 20 \mathrm{IU}, 30 \mathrm{IU}$, and $50 \mathrm{IU}$, respectively $(P<0.0001)$. In contrast to the 1 -month evaluation, the highest dose group showed a higher healing rate $(83.1 \%)$ than patients in the medium (79.3\%) and low (64.8\%) dose groups $(P<0.0001)$. At the 2 -month evaluation, the injection site correlates statistically with healing (healing rate $59.2 \%$ and $82.1 \%$ in the posterior or anterior injection, respectively, $P<0.0001$ ).

In the multivariate analysis (Table 5), the following variables were independent factors for healing rate: pain after evacuation $(P=0.0008)$ and dose of toxin injected $(P<0.00001)$. At 2 months, both the dose of toxin injected $(P=0.004)$ and the injection site $(P=0.01)$ correlate with the healing rate (Table 6).

\section{Discussion and conclusions}

Data confirmed that chronic AF affects otherwise healthy subjects [29]. The clinical picture is so characteristic that it is diagnostic. In our study, 985 patients complained of post-defecatory pain; bleeding was present in 676 patients 
(67.4\%). Regarding bowel movements, 459 patients (45.8\%) reported constipation and $490(48.9 \%)$ evacuation of hard stools. In accord with literature [12], no marked incidence in one sex over the other or in different age groups have been observed.

Spasm of the internal anal sphincter has been observed in association with chronic AF. For many years, the aim of the treatment has been to reduce hypertonia of the sphincter. Botulinum toxin has been used to treat chronic AF while averting the risk of permanent injury of the internal anal sphincter [30-32]. The toxin induces a significant reduction in the resting anal tone [26, 32]. Furthermore, the toxin was shown to be superior to nitro derivatives in inducing healing of chronic $\mathrm{AF}[26,27,33,34]$.

Botulinum toxin injection is easier to perform than surgery. In this series, in $94.1 \%$ of the treatments, no local anesthesia and/or systemic sedation was used, and in $93.9 \%$ of patients, the sphincter was easily identified with simple digital palpation. In $0.1 \%$ of cases, a local reaction occurred, consisting of a limited and modest skin rash, which resolved after 4 days following the topical application of corticosteroids.

The toxin can be used safely for the treatment of chronic AF, particularly in patients at risk of incontinence [24]. The toxin is a safe treatment and has several advantages over other methods [29]. In the present study, healing was observed in $74.9 \%$ of patients at 1 -month evaluation. After 2 months, a complete healing was evident in $77.7 \%$ of patients. Healing remained stable for a period of $71.4 \pm 38.6$ months. No demographic parameters were shown to have a direct influence on healing. We did not observe AF recurrence in the patient population treated. This finding is probably linked to the fact that in most of our patients, the fissure had appeared less than 7 months before and that most of the patients had undergone treatment with at least 30-100 IU of toxin. Few studies assess long-term recurrence. Some of these studies document a trend to progressive recurrence over time, with lower healing rates than those initially reported [35]. These results could be related to the reversible effect of the toxin and the natural history of the disease. It has also been showed that recurrence occurred mainly between 6 and 12 months, so later relapses were not expected. Other findings in the literature proved that the efficacy of botulinum toxin was maintained during a longterm follow-up (5 years), with a negligible recurrence rate at 1 year (11.4\%), and no recurrence at 3 and 5 years of follow-up [1].

The result of the present study also confirms that the use of higher doses and the availability of a rescue treatment account for a higher success rate, without any increase of complications or side effects. As previously reported, manometric data have shown that the internal anal sphincter is weakened after the injection and that no significant diffusion to the external sphincter takes place.
We observed that toxin dose significantly correlates with healing rate, as reported in other studies [36, 37]. The higher the dose used, at least up to $50 \mathrm{IU}$, the more conspicuous the number of patients healed. It has been documented that higher dosages of toxin induce healing in a larger number of patients, also determining a more significant decrease in resting anal tone. The reduction of the resting anal tone is, moreover, an event directly correlated to the toxin dose: The higher the dose used, the faster and more marked the decrease in resting anal tone. Diffusion of toxin in the tissue is a dose-dependent phenomenon. Histochemical staining of acetylcholinesterase suggested that higher doses produced a biological effect throughout the entire muscle, whereas smaller doses produced a gradient down the length of the muscle studied [38]. The dose of toxin injected directly correlates with the results $[36,37,39,40]$. At univariate analysis, our study confirmed that the dose of toxin correlated significantly with healing. At 2 months evaluation, the higher dose group (50-100 IU) showed a higher healing rate $(83.1 \%)$ than patients in the medium $(79.3 \%)$ and low $(64.8 \%)$ groups dose $(P<0.0001)$.

Another parameter strongly correlated with healing is the injection site. Healing was apparent in $56.6 \%$ of patients injected at the posterior midline and in $78.6 \%$ of those with toxin administration at the level of the anterior commissure, as reported in another study [41]. We hypothesized that botulinum toxin action on the internal anal sphincter depends upon the muscle fiber response and that the toxin is more effective in a non-ischemic sphincter. Brown and coworkers [42] have underlined that a myositis involving internal anal sphincter close to the fissure site can develop early in chronic AF patients, causing fibrosis. The fibrosis was more prominent at the base of the fissure; it could reduce compliance of the internal anal sphincter and might block the toxin action. Moreover the blood supply of the anoderm at the posterior midline was found to be significantly lower than the other sides of the anal canal. A significant relationship between anal pressure and anodermal blood flow was demonstrated at the posterior midline, and morphometric study of the capillaries revealed them to be less dense both in the subanodermal space and within the internal anal sphincter [43]. The myenteric plexus with myenteric ganglia was located between the circular and longitudinal smooth muscle layers for the whole extent of the internal anal sphincter. It seems conceivable that fibrosis or ischemia at the base of the posterior fissure may destroy the myenteric nervous fibers and, when using botulinum toxin in this site, a variable clinical response can be observed. Botulinum toxin may induce healing by simple increasing local blood flow or by a more complex effect. It has been shown that botulinum toxin does not block non-adrenergic noncholinergic responses, which are mediated by nitric oxide [30]. At multivariate analysis, 
a significant correlation was documented with the injection site $(P=0.01)$.

In this study, we did not observe any differences in the clinical efficacy of the two different preparations of botulinum toxin type A available on the market, at a conversion factor of 1 to 3 as reported in the literature for the treatment of affections of the striated muscles. These findings confirm our previous observation on 100 patients with chronic anal fissure [28].

In conclusion, we confirm that the botulinum toxin is a safe treatment for AF patients. We find it effective and easier to perform compared to surgery. The best results were obtained when, in patients with posteriorly located fissure, the toxin was injected into the internal sphincter at the anterior commissure. The optimal dose was found to be $50 \mathrm{IU}$ of American toxin or $150 \mathrm{IU}$ of British formulation. We have noted that higher dosages induce a statistically significant increase in the healing rate without increasing complications.

Author contribution Study conception and design: Brisinda G, Chiarello MM, Bentivoglio AR, Vanella S. Acquisition of data: Crocco A, Cariati M, Vanella S. Analysis and interpretation of data: Brisinda G, Chiarello MM, Vanella S. Drafting of manuscript: Brisinda G, Chiarello MM. Critical revision: Chiarello MM, Vanella S. All authors have participated sufficiently in the work to take public responsibility for its content.

\section{Declarations}

Ethics approval All authors state that the protocol for the research project has been approved by a suitably constituted Ethics Committee of the institution within which the work was undertaken and that it conforms to the provisions of the Declaration of Helsinki of 1975.

Informed consent Each patient has been informed about the modalities and purposes of the treatment, providing, in all cases, written consent.

Conflict of interest The authors declare no competing interests.

Open Access This article is licensed under a Creative Commons Attribution 4.0 International License, which permits use, sharing, adaptation, distribution and reproduction in any medium or format, as long as you give appropriate credit to the original author(s) and the source, provide a link to the Creative Commons licence, and indicate if changes were made. The images or other third party material in this article are included in the article's Creative Commons licence, unless indicated otherwise in a credit line to the material. If material is not included in the article's Creative Commons licence and your intended use is not permitted by statutory regulation or exceeds the permitted use, you will need to obtain permission directly from the copyright holder. To view a copy of this licence, visit http://creativecommons.org/licenses/by/4.0/.

\section{References}

1. Barbeiro S, Atalaia-Martins C, Marcos P, Goncalves C, Canhoto M, Arroja B et al (2017) Long-term outcomes of Botulinum toxin in the treatment of chronic anal fissure: 5 years of follow-up. United European Gastroenterol J 5:293-297

2. Boland PA, Kelly ME, Donlon NE, Bolger JC, Larkin JO, Mehigan BJ et al (2020) Management options for chronic anal fissure: a systematic review of randomised controlled trials. Int J Colorectal Dis 35:1807-1815

3. Brisinda G, Vanella S (2009) Chronic anal fissure: surgical or reversible neurochemical sphincterotomy? Nat Rev Gastroenterol Hepatol 6:694-695

4. Sajid MS, Hunte S, Hippolyte S, Kiri VA, Maringe C, Baig MK (2008) Comparison of surgical vs chemical sphincterotomy using botulinum toxin for the treatment of chronic anal fissure: a metaanalysis. Colorectal Dis 10:547-552

5. Nelson RL, Thomas K, Morgan J, Jones A (2012) Non surgical therapy for anal fissure. Cochrane Database Syst Rev 2:CD003431

6. Sahebally SM, Meshkat B, Walsh SR, Beddy D (2018) Botulinum toxin injection vs topical nitrates for chronic anal fissure: an updated systematic review and meta-analysis of randomized controlled trials. Colorectal Dis 20:6-15

7. Chiarello MM, Cariati M, Brisinda G (2020) Botulinum toxin versus other therapies for treatment of chronic anal fissure. Coloproctology 42:457-463

8. Alawady M, Emile SH, Abdelnaby M, Elbanna H, Farid M (2018) Posterolateral versus lateral internal anal sphincterotomy in the treatment of chronic anal fissure: a randomized controlled trial. Int J Colorectal Dis 33:1461-1467

9. Shao WJ, Li GC, Zhang ZK (2009) Systematic review and metaanalysis of randomized controlled trials comparing botulinum toxin injection with lateral internal sphincterotomy for chronic anal fissure. Int J Colorectal Dis 24:995-1000

10. Acar T, Acar N, Gungor F, Kamer E, Gungor H, Candan MS et al (2019) Treatment of chronic anal fissure: is open lateral internal sphincterotomy (LIS) a safe and adequate option? Asian J Surg 42:628-633

11. Higuero $\mathrm{T}$ (2015) Update on the management of anal fissure. $\mathbf{J}$ Visc Surg 152:S37-43

12. Lindsey I, Jones OM, Cunningham C, Mortensen NJ (2004) Chronic anal fissure. Br J Surg 91:270-279

13. Davies I, Dafydd L, Davies L, Beynon J (2014) Long term outcomes after lateral anal sphincterotomy for anal fissure: a retrospective cohort study. Surg Today 44:1032-1039

14. Siddiqui J, Fowler GE, Zahid A, Brown K, Young CJ (2019) Treatment of anal fissure: a survey of surgical practice in Australia and New Zealand. Colorectal Dis 21:226-233

15. Utzig MJ, Kroesen AJ, Buhr HJ (2003) Concepts in pathogenesis and treatment of chronic anal fissure-a review of the literature. Am J Gastroenterol 98:968-974

16. Zbar AP, Pescatori M (2004) Functional outcome following lateral internal anal sphincterotomy for chronic anal fissure. Colorectal Dis 6:210-211

17. Garg P, Garg M, Menon GR (2013) Long-term continence disturbance after lateral internal sphincterotomy for chronic anal fissure: a systematic review and meta-analysis. Colorectal Dis 15:e104-e117

18. Chen HL, Woo XB, Wang HS, Lin YJ, Luo HX, Chen YH et al (2014) Botulinum toxin injection versus lateral internal sphincterotomy for chronic anal fissure: a meta-analysis of randomized control trials. Tech Coloproctol 18:693-698

19. Gandomkar H, Zeinoddini A, Heidari R, Amoli HA (2015) Partial lateral internal sphincterotomy versus combined botulinum toxin 
A injection and topical diltiazem in the treatment of chronic anal fissure: a randomized clinical trial. Dis Colon Rectum 58:228-234

20. Bhama AR, Zoccali MB, Chapman BC, Davids JS, Eisenstein S, Fish DR et al (2021) Practice variations in chemodenervation for anal fissure among American Society of Colon and Rectal Surgeons Members. Dis Colon Rectum 64:1167-1171

21. Borsuk DJ, Studniarek A, Park JJ, Marecik SJ, Mellgren A, Kochar K (2021) Use of botulinum toxin injections for the treatment of chronic anal fissure: results from an American Society of Colon and Rectal Surgeons Survey. Am Surg 31348211023446

22. Yiannakopoulou E (2012) Botulinum toxin and anal fissure: efficacy and safety systematic review. Int J Colorectal Dis 27:1-9

23. Brisinda G, Vanella S, Crocco A, Maria G (2012) Type A botulinum toxin treatment for chronic anal fissure. Int J Colorectal Dis 27:1543-1545

24. Bobkiewicz A, Francuzik W, Krokowicz L, Studniarek A, Ledwosinski W, Paszkowski J et al (2016) Botulinum toxin injection for treatment of chronic anal fissure: is there any dose-dependent efficiency? A MetaAnalysis. World J Surg 40:3064-3072

25. Cariati M, Chiarello MM, Cannistra M, Lerose MA, Brisinda G (2021) Gastrointestinal uses of botulinum toxin. Handb Exp Pharmacol 263:185-226

26. Brisinda G, Maria G, Bentivoglio AR, Cassetta E, Gui D, Albanese A (1999) A comparison of injections of botulinum toxin and topical nitroglycerin ointment for the treatment of chronic anal fissure. $\mathrm{N}$ Engl J Med 341:65-69

27. Brisinda G, Cadeddu F, Brandara F, Marniga G, Maria G (2007) Randomized clinical trial comparing botulinum toxin injections with 0.2 per cent nitroglycerin ointment for chronic anal fissure. Br J Surg 94:162-7

28. Brisinda G, Albanese A, Cadeddu F, Bentivoglio AR, Mabisombi A, Marniga G, et al (2004) Botulinum neurotoxin to treat chronic anal fissure: results of a randomized "Botox vs. Dysport" controlled trial. Aliment Pharmacol Ther 19:695-701

29. Brisinda G, Bianco G, Silvestrini N, Maria G (2014) Cost considerations in the treatment of anal fissures. Expert Rev Pharmacoecon Outcomes Res 14:511-525

30. Keef KD, Cobine CA (2019) Control of motility in the internal anal sphincter. J Neurogastroenterol Motil 25:189-204

31. Maria G, Brisinda G, Bentivoglio AR, Cassetta E, Gui D, Albanese A (1998) Botulinum toxin injections in the internal anal sphincter for the treatment of chronic anal fissure: long-term results after two different dosage regimens. Ann Surg 228:664-669

32. Maria G, Cassetta E, Gui D, Brisinda G, Bentivoglio AR, Albanese A (1998) A comparison of botulinum toxin and saline for the treatment of chronic anal fissure. N Engl J Med 338:217-220
33. Mathur N, Qureshi W (2020) Anal fissure management by the gastroenterologist. Curr Opin Gastroenterol 36:19-24

34. Berkel AE, Rosman C, Koop R, van Duijvendijk P, van der Palen J, Klaase JM (2014) Isosorbide dinitrate ointment vs botulinum toxin A (Dysport) as the primary treatment for chronic anal fissure: a randomized multicentre study. Colorectal Dis 16:O360-O366

35. Minguez M, Herreros B, Espi A, Garcia-Granero E, Sanchiz V, Mora F et al (2002) Long-term follow-up (42 months) of chronic anal fissure after healing with botulinum toxin. Gastroenterology 123:112-117

36. Brisinda G, Maria G, Sganga G, Bentivoglio AR, Albanese A, Castagneto M (2002) Effectiveness of higher doses of botulinum toxin to induce healing in patients with chronic anal fissures. Surgery 131:179-184

37. Ravindran P, Chan DL, Ciampa C, George R, Punch G, White SI (2017) High-dose versus low-dose botulinum toxin in anal fissure disease. Tech Coloproctol 21:803-808

38. Borodic GE, Ferrante R, Pearce LB, Smith K (1994) Histologic assessment of dose-related diffusion and muscle fiber response after therapeutic botulinum A toxin injections. Mov Disord 9:31-39

39. Soltany S, Hemmati HR, Toussy JA, Salehi D, Toosi PA (2020) Therapeutic properties of botulinum toxin on chronic anal fissure treatment and the patient factors role. J Family Med Prim Care 9:1562-1566

40. Pilkington SA, Bhome R, Welch RE, Ku F, Warden C, Harris S et al (2018) Bilateral versus unilateral botulinum toxin injections for chronic anal fissure: a randomised trial. Tech Coloproctol 22:545-551

41. Maria G, Brisinda G, Bentivoglio AR, Cassetta E, Gui D, Albanese A (2000) Influence of botulinum toxin site of injections on healing rate in patients with chronic anal fissure. Am J Surg 179:46-50

42. Brown AC, Sumfest JM, Rozwadowski JV (1989) Histopathology of the internal anal sphincter in chronic anal fissure. Dis Colon Rectum 32:680-683

43. Schouten WR, Briel JW, Auwerda JJ, De Graaf EJ (1996) Ischaemic nature of anal fissure. Br J Surg 83:63-65

Publisher's Note Springer Nature remains neutral with regard to jurisdictional claims in published maps and institutional affiliations. 